\title{
A Study on the Effectiveness of TPR and TPRS in Short-Term Chinese Language Training at the Beginner Level
}

\author{
Ming Chang \\ School of Foreign Languages \\ Hangzhou Normal University \\ Hangzhou, China \\ victoriacm@163.com
}

\author{
Jing Chen \\ School of Foreign Languages \\ Hangzhou Normal University \\ Hangzhou, China \\ jeanchan78@163.com
}

\begin{abstract}
TPR and TPRS enjoyed worldwide popularity among language instructors. An empirical research was carried out in a Summer Program targeting children and teenagers followed by another study targeting adults. The learning results are productive with the overall development of learners' language abilities, which leads to a conclusion that the two language teaching methods are effective for teaching Chinese as a foreign language on a short term basis. However, the instructors face great challenges in application and further studies are required.
\end{abstract}

Keywords-TPR; TPRS; effective; Chinese as a foreign language; acquisition

\section{INTRODUCTION}

Language teachers on a worldwide scale have been searching all the time for the answer to the question of how to teach effectively, and they've used, tested, and experimented with many language teaching methods. This question was answered in the 1960s by James Asher who initiated Total Physical Response (TPR), a language teaching method through which learners learn by actions [1]. Later on, language classes using TPR have enjoyed successful results for students acquiring European, Asian, Indian and Semitic languages [2]. Teaching Proficiency through Reading and Storytelling (TPRS), another teaching method for foreign language acquisition was invented by Blaine Ray in 1990. TPRS combines Asher's TPR with Stephen Krashen's language acquisition strategies, allowing teachers to teach reading and writing along with vocabulary through story telling [3].

The first author was introduced to the world of TPR and TPRS by Dr. Shelly Thomas, a friend to Asher and the founder and director of the Center for Accelerated Language Acquisition (CALA). Since then, she has been practicing these two methods in her Chinese classes in a kindergarten, a primary school, and a university in the United States. The application of the two methods is proved to be fun, effective and highly engaging.

However, the use of TPR and TPRS at a five-day summer camp program and a two-session Chinese training class reveals that their effectiveness is even prominent in teaching Chinese as a foreign language at the beginner level on a short term basis
The first author was honored to present her study in the Tennessee Foreign Language Teaching Association and 2013 SECLA Conference hosted by North Carolina State University, where the audience showed great interest in her studies. It was their enthusiasm that motivated the authors to write this paper.

This paper aims to reveal the effectiveness of TPR and TPRS in short-term language class at the beginner level. Major findings and challenges are discussed to enlighten future studies.

\section{LITERATURE REVIEW}

\section{A. What are TPR and TPRS?}

TPR is a language teaching method, which is built around the coordination of speech and action and attempts to teach language through physical activities [4]. The instructor physically and verbally models commands in the target language for the students, who are then required to respond in proper actions; then, the instructor hesitates to observe the students' comprehension; s/he stops modeling when the students give a quick response to his/her commands individually as a sign of internalization. The theory of this TPR process is based on Krashen's "comprehensible input", according to which language is not learned but acquired in a natural way [5].

Inspired by TPR, Ray found that telling a story assisted by physical actions and asking the students to act out the story preserved the effective physical element [3]. The students' motivation can be increased by the desire to tell stories [6]. TPRS utilizes vocabulary first taught, using TPR by incorporating it into stories that students hear, watch, act out, retell, revise, read, write, and rewrite. Subsequent stories introduce additional vocabulary in meaningful contexts [7].

\section{B. The effectiveness of TPR and TPRS}

Since this invention, the originator of TPR, Asher has conducted a series of experimental research, which shows that children learn a foreign language better through TPR than those who learn by traditional methods [8]. Many teachers and scholars collected empirical evidence on the effectiveness of teaching either children or adults foreign languages through 
TPR, such as Japanese as in [4], Spanish as in [9] and [10], Russian as in [11] and American Indian languages as in [7] and [12]. Along with the popularity of TPR, TPRS is considered as a successful teaching method for foreign language acquisition as well [3]. In the 2000s, TPRS was introduced into Chinese classes and won its popularity in international schools in China. It has become an effective method for teaching Chinese as a foreign language according to $\mathrm{Li}[8]$.

Although there are several publications as in [14] and [15] available about how to use TPR to teach intermediate and advanced students, according to the Routledge Encyclopedia of Language Teaching and Learning [13], TPR is often criticized as being only suitable for beginning students [16].

\section{APPLICATION OF TPR AND TPRS IN OUR STUDY}

\section{A. Why were TPR and TPRS adopted?}

The first author served as a Chinese teacher in a one-week Summer Program which included classes of Chinese and others at The Webb School, located in Bell Buckle, Tennessee in the summer of 2013. The campers took part in 45-minute long Chinese session for five consecutive days. The first 15 minutes of the Chinese class was allocated to a brief introduction of the Chinese language and China and the last 15 minutes for a paper cutting activity, so the accumulative training time was 3 hours and 15 minutes.

Given such a job at the beginner level, the question is about what to teach and how to teach it. The purpose of prior experiences from many short-term language programs is to "have fun and learn a new language at the same time"1 however, those programs explain the fun activities in great detail with only simple mentioning of the language part, such as building their foreign language vocabularies ${ }^{2}$ and the focus on "conversational skills"3. In this case, the adoption of TPR and TPRS is able to fully serve the purposes of these language programs by engaging students in fun activities in a stress-free and supportive learning environment. Learning doesn't only happen on lexical level and syntactic level but also on discoursal level with integrated drills on listening, speaking, reading and writing provided.

\section{B. How were TPR and TPRS adopted and adapted?}

In the Summer Program, the target learners were children and teenagers in mixed age groups: two younger groups (Grade 3-5), two older groups (Grade 6-8). Class size was 8-12 individuals. They were expected to learn some basic vocabulary and sentence structures and tell a story in Chinese, gain a sense of achievement and use what they learned in real life.

The very beginning learning was to use a greeting sentence "Nǐ hăo, wǒ jiào..." (Hello, my name is...) on a conversational level and students were encouraged to say their Chinese names

\footnotetext{
Berlitz Kids \& Teens Summer Camp programs, [online] Available at $<$

http://www.berlitz.us/individual-solutions/language-instruction-kids-teens/summer-languagecamp-programs-for-kids-and-teens/ $>(15 / 9 / 2015$ 13:28

${ }^{2}$ Half-day themed camps, Summer Programs, [online] Available at $<$

$\mathrm{http}: / /$ coursehorse.com/kids-language-classes-la/summer-camp2> (15/9/2015 20:21)

3 Language Camps in Houston, TX, [online] Available at $<$

http://www.crossingborderslanguages.com/camps.html $>(3 / 8 / 2015$ 10:07)
}

which they knew from name cards in Pinyin (the Chinese Phonetic Alphabet) and Chinese characters earlier.

After knowing each other, they came into the word learning process. Listening ability and vocabulary are developed first and then speaking [17]. TPR-able words including verbs "zǒu" (walk), "shuō" (say), "chī" (eat) etc. and adverbs "kuài" (fast), "màn" (slowly), were introduced and drilled until they could be understood and pronounced correctly and instinctively. NonTPR-able words, such as "xióng māo" (panda), were presented in pictures which could be easily associated with their meanings, so that the students learned without relying on their first language.

The following phase was sentence learning. The leading sentence structure was "... zǒu dào ... " (Someone walks to someplace). Students were commanded to walk to different places in the classroom where pictures were posted to set up various situations.

With the building of vocabulary and sentence structures, leaning came to discoursal level. After the introduction of the assisting vocabulary and phrases, the instructor told the story in Chinese while acted it out simultaneously. Then the students watched a story picture and listened to the story at the same time. Later, they were asked to tell the story in English so that the instructor could make sure that they could fully understand the story. If so, they were asked to read the story in Pinyin first silently and then loudly after the modelling. In the end, students were encouraged to tell the story in Chinese by looking at the story picture only.

The last part was creative writing. Divided in groups, students were asked to make stories, draw story pictures and write down the stories in Pinyin. Of course, new words would be given if they were needed.

Each learning phase is chronologically and logically connected to the subsequent parts. The earlier acquisition even the very first step - the greeting sentence — supports future learning. Any disorder in sequence may retard the learning process. Therefore, the success of the teaching lies to a great extent in the class design, as explained by Asher as in [17], "It is wise to write out the exact utterances you will be using and especially the novel commands because the action is so fastmoving there is usually not time for you to create spontaneously."

\section{Learning outcomes}

The learning outcomes will be evaluated in the following domains: listening, speaking, reading and writing.

What was achieved first is listening ability. All the students were able to respond to the instructor's commands of ten verbs and the twenty combinations of the ten verbs with two adverbs; they were able to get to the designated place hearing the command structure " ...zǒu dào...". When someone was telling the story, the other students could give comments by saying "hăo" (good), "bùhăo" (not good, bad), "zāogāo" (terrible) at the proper time, which meant they had no problem understanding the story. According to Asher, students can learn between 12 and 36 words every hour of instruction, depending 
on their language level and class size as in [18], while in this case students learned 12 words in 30 minutes.

Six students called on at random were required to tell the story. One of them could retell the story exactly the same way as it was told, and clearly pronounced all words; three students could tell the story with a few missing sentence elements, such as the subject or the object; two of them spoke some sentences which were not in the logical order of the story, but they showed the ability to continue their utterance and the pleasure of doing so. The speaking outcome was still striking considering the limited learning time.

Two reading exercises were followed after the story reading process. The first exercise was to put the listed sentences in the correct order and the second one was to fill in the blanks with a word from the word bank. Both exercises were designed based on the story. The students finished the exercises in a short time with great accuracy and they showed no difficulty in completing them.

Eight stories along with eight story pictures were collected, the process of which is considered as a deviation of timed writing. It is highly likely that timed writing, the number of words students can write in a given amount of time, is a valid measure of proficiency as in [19]. The number of words in a story ranges from 27 to 40 in this case.

Additionally, this Chinese class enjoyed a positive review from an anonymous post-teaching survey answered by the parents, which serves as strong evidence that the adoption of TPR and TPRS is qualified for such a program. One parent told the director afterwards that her son was totally engaged and wanted more training while the director was planning on the Chinese Culture and Language class to be doubled in length as parents requested.

\section{A follow-up study}

The effectiveness of TPR and TPRS in teaching children and teenagers is confirmed in learning outcomes, but how effective are they in teaching adults? The authors carried out another study targeting 8 adult learners aged from 19 to 36 who had 6 hours of Chinese learning experience before this class. The results are that adults outperformed the children in understanding a new language as in [20] and their writing was longer and more complicated compared than those of the children and teenagers. However, children, rather than adults, have a "biological" advantage in acquiring a native pronunciation of the new language [21].

\section{MAJOR FINDINGS AND CHALLENGES}

Krashen's Natural Order Hypothesis claims that learners acquire the different parts of a language in a predictable order. Some researchers argue that students should be exposed to the target language for a considerable length of time before being asked to produce any words as in [22], otherwise the process will more than likely fail [23]. The time delayed for utterance is about two weeks as in [8] or weeks [23]. However, in the present study, students were able to speak in the target language several minutes after the input when they could respond easily to the commands, while they showed no reluctance to speak, but excitement instead. Thus, the expected duration for confidence and readiness for utterance is not necessarily a long time.

Moreover, the target culture can be introduced by embedding it in TPRS. Anderson [24] suggests that making a connection between the language by combining history and culture in a succinct yet engaging story is a helpful way. The instructor included some cultural elements, such as xióng māo (panda) and bāozi (steamed dumpling) in the story, and more than that, sentences based on conversational level were integrated so that the students could use them in a real life situations, such as at a restaurant.

One major challenge in using TPR and TPRS is that the instructors should be sufficiently prepared. They had better go through a systematical training and have practiced the two approaches at least for a while so that they could provide quality input, via which acquisition is much faster. The job is more difficult without supportive teaching materials adopting TPRS as the main teaching method in teaching Chinese as foreign language.

Used wisely, the methods are highly productive. However, another problem arises after a couple of training sessions in that the students' language proficiency showed great variations To maintain the effectiveness, teachers can divide students into new learning groups, which is often an expectation rather than a possibility in real teaching situations. Therefore, the authors argue that TPR and TPRS are more effective in short-term language training at the beginner level although they have been proved to be effective in other situations as discussed in the second part of this paper.

\section{CONCLUSION}

TPR and TPRS are found to be effective teaching methods for the teaching of Chinese as a foreign language on a short term basis based on the study of real classroom teaching either to children, teenagers or adults.

Language learners were attentively engaged and the study showed significant learning outcomes. The input of the language occurred comprehensively to them through all the senses in a comfortable classroom environment. And the acquisition evolved listening, speaking, reading and writing in a an engaging manner, which led to a more productive and innovative output.

Learners can produce utterances naturally in a short time after receiving language input instead of weeks delay for readiness. Cultural information and conversational structures can be embedded in the story to make language production diversified. While the instructors face a great challenge of lack of supporting materials, which means plenty of extra work needs to be done by they themselves. Another challenge is that the accumulative learning effect may cause a variation of students' language abilities, which makes future teaching a difficult task. Of course, no method can handle the teaching task single handedly. To achieve the maximum effect, other methods can be integrated to work as necessary supplements.

This study, although carefully designed and carried out, failed to collect participants' direct feedback except the reviews from the parents, which can be considered as a 
limitation of the study. Future studies should supposedly focus more on the comparison of the effectiveness between TPR and TPRS and other language teaching methods.

\section{REFERENCES}

[1] J. J. Asher, "The total physical response approach to second language learning," MLA, H. Byrnes. Malden, MA: Wiley-Blackwell, vol. 53, iss. 1, pp. 3-17, January 1969

[2] J. J. Asher, "TPR: After forty years, still a very good idea," unpublished.

[3] B. Ray and C. Seely, Fluency Through TPR Storytelling, $5^{\text {th }}$ ed.. CA: Blaine Ray Workshops \& Command Performance Language Institute, 1997.

[4] J. J. Asher, J. A. Kusudo, and Rita De La Torre, "Learning a second language through commands: the second field test," MLA, H. Byrnes. Malden, MA: Wiley-Blackwell, vol. 58, iss. 1-2, pp. 24-32, JanuaryFebruary 1974.

[5] S. D. Krashen, Foreign language Education The Easy Way. Culver City, CA: Language Education Associates, 1997.

[6] K. Nguyen, N. Stanley, and L. Stanley, "Storytelling in teaching Chinese as a second/foreign Language," Linguistics and Literature Studies, M. Lee. CA: Horizon Research Publishing, vol. 2, iss. 1, 2014 pp.29-38.

[7] G. P. Cantoni, "Using TPR-Storytelling to develop fluency and literacy in aative American language," Revitalizing Indigenous Languages, J. Reyhner. AZ: Northern Arizona University, 1999, pp. 53-58.

[8] N. Li, "Is TPRS an effective method for teaching Chinese as a foreign language among young learners of beginning levels?" unpublished.

[9] E. W. Glisan, "Total physical response: a technique for teaching all skills in spanish," Foreign Language Annals, A. Nerenz and E. Mich., Eds. Malden, MA: Wiley-Blackwell, vol. 19, iss. 5, pp. 419-427, October 1986.

[10] L. M. Roof and C. A. Kreutter, "An interactive storytelling puzzle: building a positive environment in a second language classroom," Networks, C. F. Compton-Lilly and S. Porath, WI: University of Wisconsin Digital Collections Center, vol. 12, iss. 1, 2010, pp. 1-10.
[11] E. Elliott and L. Yountchi, "Total physical response and Russian multiand unidirectional verbs of motion: a case study in acquisition", SEEJ, Special Forum Issue: Teaching and Learning Russian Verbs of Motion, P. Zody. Washington DC: the American Association of Teachers of Slavic and East European Languages, vol. 53, 2009, pp. 428-450.

[12] P. Thompson, "Teaching the HoChank 'Ho Chunk' language with TPR," unpublished.

[13] M. Byram, Routledge Encyclopedia of Language Teaching and Learning. Routledge: Taylor \& Francis, 2000.

[14] E. Schessler, English Grammar through Actions. Los Gatos, CA: Sky Oaks Productions, 1986.

[15] K. M. Bailey, Practical English Language Teaching: Speaking. New York: McGraw-Hill ESL/ELT, March 2007.

[16] M. Byram, Routledge Encyclopedia of Language Teaching and Learning. London: Routledge, 2000.

[17] S. D. Krashen, Principles and Practice in Second Language Acquisition. Oxford: Pergamon Press, 2009.

[18] J. C. Richards, and T. S, Rodgers, Approaches and Methods in Language Teaching, 2nd ed.. Cambridge, New York: Cambridge University Press, 2001

[19] S. D. Krashen, "Contributions, Problems, New Frontiers, and Issues," unpublished.

[20] J. J. Asher, "The total physical response (TPR): review of the evidence" unpblished.

[21] J. J. Asher, and R. Garcia, "The optimal age to learn a foreign language," MLA, H. Byrnes. Malden, MA: Wiley-Blackwell, vol. 53, iss. 1, pp.334-341, January 1969

[22] S. D. Krashen, " Principles and Practice in Second Language Acquisition". Oxford: Pergamon, 1982.

[23] M. Blanton, "The effect of two foreign language teaching approaches, communicative language teaching and teaching proficiency through reading and storytelling, on motivation and proficiency for Spanish III students in high school," unpubished.

[24] S. M. Anderson, "Connecting Language and Culture Through Storytelling", unpublished. 